\title{
ENSO influence on Europe during the last centuries
}

\author{
S. Brönnimann · E. Xoplaki · C. Casty · \\ A. Pauling $\cdot$ J. Luterbacher
}

Received: 20 February 2006/ Accepted: 22 June 2006/ Published online: 26 July 2006

(C) Springer-Verlag 2006

\begin{abstract}
El Niño/Southern Oscillation (ENSO) affects climate not only in the Pacific region and the tropics, but also in the North Atlantic-European area. Studies based on twentieth-century data have found that El Niño events tend to be accompanied in late winter by a negative North Atlantic Oscillation index, low temperatures in northeastern Europe and a change in precipitation patterns. However, many questions are open, for example, concerning the stationarity of this relation. Here we study the relation between ENSO and European climate during the past 500 years based on statistically reconstructed ENSO indices, early instrumental station series, and reconstructed fields of surface air temperature, sea-level pressure, precipitation, and $500 \mathrm{hPa}$ geopotential height. After removing years following tropical volcanic eruptions (which systematically mask the ENSO signal), we find a consistent and statistically significant ENSO signal in late
\end{abstract}

S. Brönnimann $(\bowtie)$

Institute for Atmospheric and Climate Science,

ETH Zürich, Universitätsstr. 16, 8092 Zürich, Switzerland

e-mail: stefan.broennimann@env.ethz.ch

E. Xoplaki $\cdot$ J. Luterbacher

NCCR Climate, University of Bern, Bern, Switzerland

E. Xoplaki · J. Luterbacher

Institute of Geography, Climatology and Meteorology,

University of Bern, Bern, Switzerland

C. Casty

Physics Institute, University of Bern, Bern, Switzerland

A. Pauling

MeteoSwiss, Zürich, Switzerland winter and spring. The responses to El Niño and La Niña are close to symmetric. In agreement with studies using twentieth-century data only, the ENSO signal in precipitation is different in fall than in late winter. Moving correlation analyses confirm a stationary relationship between ENSO and late winter climate in Europe during the past 300 years. However, the ENSO signal is modulated significantly by the North Pacific climate. A multi-field cluster analysis for strong ENSO events during the past 300 years yields a dominant pair of clusters that is symmetric and represents the "classical' ENSO effects on Europe.

\section{Introduction}

El Niño/Southern Oscillation (ENSO) is the globally dominating mode of interannual climate variability and affects weather and climate worldwide. Because of the progress that has been made in its prediction, the relation between ENSO and climate in other regions is of interest with respect to potential seasonal predictability. This is especially the case for Europe, where current forecast systems have almost no skill on the seasonal scale (van Oldenborgh 2005).

The effect of ENSO on climate in Europe has been studied intensively during the past few years using both models (e.g. Merkel and Latif 2002; Mathieu et al. 2004) and observational data (e.g. Fraedrich and Müller 1992; Gouirand and Moron 2003; Pozo-Vázquez et al. 2005; Mariotti et al. 2005; Brönnimann et al. 2004). Many authors find that the predominant response pattern to ENSO of the circulation over the North Atlantic-European sector in late winter is similar to, though not exactly, the North Atlantic 
Oscillation (NAO), with a negative sign for El Niño and a positive for La Niña. It includes (for the El Niño case) low temperatures over northeastern Europe and negative and positive precipitation anomalies in Norway and around $40-45^{\circ} \mathrm{N}$ (including large parts of the Mediterranean), respectively. However, there are still many open questions. For instance, the signal is rather difficult to detect within the large interannual variability of climate in the North Atlantic-European sector. Some authors suggest that the response might be non-stationary in time or that there might be several distinct, robust ENSO signals (e.g. Moron and Gouirand 2003; Knippertz et al. 2003; Greatbatch et al. 2004; Raible et al. 2004; see also discussion in van Oldenborgh and Burgers 2005).

It is therefore interesting to use very long records and study the ENSO signal in Europe at a seasonal time scale further back in time than the observational record allows. This can only be done with spatio-temporally highly resolved climate field reconstructions. Proxy climate data stand as our only means of assessing the long-term variability associated with ENSO and its global influence. Mann et al. (2000a) review the recent publications of ENSO reconstructions based on a variety of natural and documentary proxies.

Mann et al. (2000a) show reconstructed global annual mean temperature anomalies for a number of $\mathrm{El}$ Niño years since 1650 (1652, 1720, 1747, 1791, 1804, 1828, 1877 and 1884, selected based on documentary evidence). Except for 1791, all of them show negative or neutral temperature departures over northeastern Europe. However, the anomaly fields presented for two La Niña years, that is, 1732 and 1777, also show below normal temperatures in northeastern Europe. In a statistical analysis of the same data, a negative or neutral temperature signal in northeastern Europe during El Niño is found in all studied subsequent 50year periods, whereas other signals, such as the temperature response over southwestern Europe were more variable and changing sign. Felis et al. (2000) and Rimbu et al. (2003) compared an oxygen isotope record from corals from the northern Red Sea with an ENSO index over the past 245 years and found a clear wintertime signal, but also noted a non-stationary behaviour of that signal around 1970. While both studies confirm ENSO effects in the greater European region prior to the instrumental record, further insight is limited by the time resolution of their records and the fact that only temperature is considered.

In this study we use reconstructed monthly and seasonal fields of sea-level pressure (SLP), land surface air temperature, precipitation, and $500 \mathrm{hPa}$ geopotential height (GPH) over the North Atlantic-European area as well as several long instrumental series to study the effect of ENSO during the past 250 to 500 years. The climate field reconstructions are compared to reconstructed ENSO indices. Using such a large sample, we address the possible non-stationary behaviour of the climate signal as well as its interaction with other climate variations.

In Sect. 2 we describe the data used (ENSO and other reconstructed indices, climate field reconstructions, early instrumental data) as well as the statistical methods, such as compositing, moving-window correlation, and clustering. Results are presented in Sect. 3 and discussed in the context of other studies. In Sect. 4, conclusions are drawn with respect to our understanding of the ENSO-European climate coupling.

\section{Data and methods}

\subsection{ENSO indices}

In order to measure ENSO, a number of indices and data sets were used. Figure 1 gives a schematic overview. Observational sea-surface temperature (SST) data to derive an SST-based ENSO index, such as NINO3 or NINO3.4 [SST averages over the areas $\left(150-90^{\circ} \mathrm{W}, 5^{\circ} \mathrm{S}-5^{\circ} \mathrm{N}\right)$ and $\left(170-120^{\circ} \mathrm{W}, 5^{\circ} \mathrm{S}-5^{\circ} \mathrm{N}\right)$, respectively] reach back to the mid-nineteenth century. We used ERSST version 2 data (Smith and Reynolds 2004) for this purpose. However, the data prior to about 1880 are uncertain in the tropical Pacific (Smith and Reynolds 2004) and hence were not used. For earlier time periods, we relied on statistical reconstructions of ENSO indices that are based on natural proxies. In order to obtain a balanced view, we used several indices. Mann et al. (2000b) reconstructed a cold season (October-March) NINO3 index back to 1650 using a multi-proxy approach. An alternative data set is a tree-ring based reconstruction of a winter (December-February) NINO3 index by Cook (2000) back to 1400 (D'Arrigo et al. 2005a). Stahle et al. (1998) reconstructed the Southern Oscillation index (SOI) based on tree rings back to 1706. In addition to these data sets, we also refer to a historical compilation of El Niño events by Quinn and Neal (1992) that reaches back to 1525 . Note that the rating of warm episodes by Quinn and Neal (1992) is qualitative and cold events are not indicated. The reliability of the record in the early centuries has been questioned; a new chronology (Ortlieb 2000) reports fewer historical El Niño events. Implications are discussed in Sect. 2.5.

Comparing the different data sets, we found that the agreement is relatively good since the early eighteenth 
century (note that the reconstructions used partly similar predictors), but poor before. For several analyses, we therefore focus on the more recent period (see later).

\subsection{Climate field reconstructions for Europe}

Several climate field reconstructions covering the North Atlantic European area were published in the past few years. We used surface air temperature reconstructions over land on a $0.5 \times 0.5^{\circ}$ grid by Luterbacher et al. (2004, updated using only temperature data as predictors; Xoplaki et al. 2005), which are based on CRU TS2.1 (Mitchell and Jones 2005). The reconstructions are seasonally resolved from 1500 to 1658, when only proxy data (tree rings, ice cores, documentary-based temperature indices, sea ice information) are available. Thereafter, early instrumental data are also used in the reconstruction approach and the fields are available on a monthly resolution. After around 1760, the main information in these reconstructions comes from early instrumental data. The reconstructions were used until 1900 and substituted with observation-based data (Mitchell and Jones 2005) thereafter. For SLP we used reconstructions by Luterbacher et al. (2002a), which were calibrated using the updated NCAR SLP data (Trenberth and Paolino 1980). The latter data were used to substitute the reconstructions after 1900. The statistical reconstructions (see Luterbacher et al. 2002a, 2004; Pauling et al. 2006 for a detailed description of the reconstruction method used) were done in a similar manner and with similar predictors as the temperature reconstructions described earlier, but on a coarser grid $\left(5 \times 5^{\circ}\right.$ in case of SLP). In addition, monthly reconstructions of $500 \mathrm{hPa}$ GPH from 1766 onward (Casty et al. 2005) were used. They are based on surface pressure observations only and were calibrated with National Centers for Environmental Prediction (NCEP)/NCAR data (Kalnay et al. 1996; Kistler et al. 2001), which were also used after 1948. Schmutz et al. (2001), Luterbacher et al. (2002a) and Brönnimann and Luterbacher (2004) showed that it is possible to statistically reconstruct high-quality upper-level pressure fields using only surface data.

Similar as for temperature, seasonal precipitation was reconstructed by Pauling et al. (2006) back to 1500 . Reconstructions are based on a large variety of long instrumental precipitation series, precipitation indices based on documentary evidence (e.g. Brázdil et al. 2005) and natural proxies (tree-ring chronologies, ice cores, corals and a speleotherm) that are sensitive to precipitation signals. The Mitchell and Jones (2005) data were used for calibration and to extend the reconstructions from 1900 to 2000.

In addition to climate field reconstructions, we also used an NAO index reconstructed by Luterbacher et al. (2002b) on a monthly basis back to 1659 , supplemented using NCAR SLP data (Trenberth and Paolino 1980; updated). Note that all of these reconstructions rely partly on the same predictor data (except for Xoplaki et al. 2005; Casty et al. 2005; Pauling et al. 2006). Hence, they are not independent from each other. In this analysis, however, the most important point is that they are independent from the El Niño indices.

\subsection{Early instrumental data}

Several early instrumental measurement series are available from Europe. In this study we considered in total 11 temperature and 11 precipitation series that reach back to 1706 (see Fig. 1; for references see Luterbacher et al. 2004; Pauling et al. 2006). All of these series were available until 1995 and quality checked regarding homogenisation issues. Most of the following analyses were also performed for all station series, but
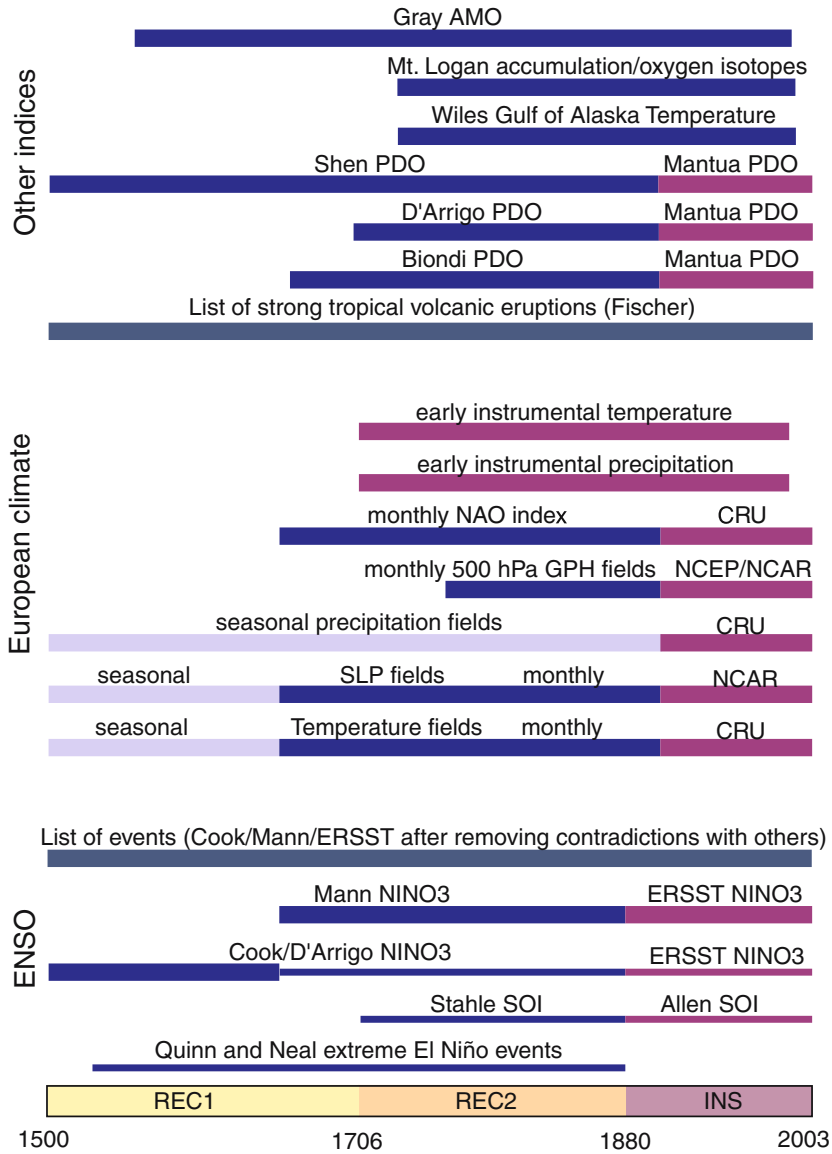

Fig. 1 Overview of the data sets used in this study 
results are only shown for two series, namely temperature in Uppsala (since 1722, Bergström and Moberg 2002) and precipitation in Paris (since 1706, Slonosky 2002). These two stations are located near the corresponding centres of the European ENSO signal in late winter (see Sect. 3.2).

Note that the same early instrumental series were also used in the climate field reconstructions. Hence the information is largely redundant (except that the station series have gaps and missing values). However, the station series allow analyses that are not possible with climate reconstructions. For instance, the variance is often underestimated in the field reconstructions, and this underestimation is time dependent. Analysing frequency distributions is therefore only possible with station data. Similarly, because reconstructions are based on the assumption of stationarity, station data are more suitable to analyse a non-stationary behaviour.

\subsection{Other climate indices}

The ENSO signal in Europe is not the same for each El Niño event and hence further factors have to be considered (see Mathieu et al. 2004). A very important disturbance is tropical volcanic eruptions, which are often followed by relatively mild winters in Europe and a positive mode of the NAO (Robock 2000); also the second winter after an eruption is, on average, affected (Fischer et al. submitted). Because tropical volcanic eruptions are often followed by El Niño conditions (Adams et al. 2003), this leads to a systematic disturbance of the European ENSO signal. Therefore, for some of the analyses we excluded the two winters following major tropical volcanic eruptions (in total 16 eruptions taken from Ammann and Naveau 2003 and Fischer et al. submitted).

The European ENSO signal possibly results from a downstream effect of the Pacific North American ENSO signal. Hence, climate conditions in the North Pacific as captured in the Pacific Decadal Oscillation (PDO, Mantua et al. 1997) or other indices are important not only as an intermediate step between the tropical Pacific and Europe, but also because they could have an effect of their own which interacts with the ENSO signal. For instance, slowly varying changes in North Pacific SST might set the stage for the downstream propagation of the ENSO signal. To address this modulating process in the pre-instrumental period, we used a number of time series that characterise climatic conditions in the North Pacific region. Reconstructions of the PDO index based on tree-ring chronologies from Southern and Baja California are available from Biondi et al. (2001) for the 1661-1991 period. Another reconstruction of an annual PDO index was published by D'Arrigo et al. (2001). It is based on western North American tree-ring records and covers the period 17001979 [their reconstruction of a spring PDO index back to 1600 (D'Arrigo et al. 2005b) is not used here]. Shen et al. (2006) reconstructed a PDO index from proxy data of summer rainfall (a drought-flood index) over eastern China. All PDO indices were supplemented with the Mantua et al. (1997) index after 1900. Another indicator of North Pacific climate is a Gulf of Alaska temperature reconstruction based on tree rings (Wiles et al. 1996). Among the three series provided by the authors we chose the April-to-September averages, which reach back to 1734. Finally, we analysed snow accumulation and oxygen isotope data from the Mt. Logan ice core that are available annually from 1736 to 2000 (Moore et al. 2002).

To address possible modulations due to Atlantic SST, we used (unfiltered) reconstructions of Atlantic SST (average from $0-70^{\circ} \mathrm{N}$ ) by Gray et al. (2004). The record goes back to 1567 (see Fig. 1) and is based on tree rings. It should be noted, however, that some of the tree ring records used are located in Europe, so this series is not independent of the signal in Europe.

\subsection{Pre-processing and selection of ENSO events}

ENSO events often reach maturity in late fall and winter, whereas the effects in northern and central Europe are expected to be largest in later winter or (for precipitation) spring (see Gouirand and Moron 2003; Knippertz et al. 2003). The ENSO indices used are defined as cold season or fall-winter indices (see earlier) and hence are expected to capture its mature phase. For the European climate signal we distinguished (where monthly means were available) late fall (OND), late winter (JFM) and late spring (AMJ). Where only seasonal means were available, however, we relied on fall (SON), winter (DJF) and spring (MAM).

In order to focus only on the interannual-to-multiannual ENSO variability, while excluding the effects of multidecadal variability, global warming or climate trends, we applied a high-pass filter. All indices, time series and fields were filtered with a Gaussian filter ( $\sigma=3$ years). The cut-off of this filter is 16 years, which effectively separates interannual-to-multiannual ENSO variability from the low-frequency signals. We refer to the high-pass filtered data also as anomalies or anomaly fields.

Among the different ENSO indices, we chose the Mann et al. (2000b) cold-season NINO3 index as our 
basis. Analysing the variances in different time periods and in the overlap between the Mann et al. (2000b) reconstructions and ERSST2, we found differences of more than a factor of 3 . Even though the variance might have increased in reality, most of this must be due to underestimated variance in the reconstructions. We therefore decided to analyse 'reconstruction period' (prior to 1880) and 'instrumental period' (from 1880 onwards) separately, wherever possible. However, in order to define 'extreme' or 'strong' events, common thresholds must be defined. For this purpose, the filtered 'reconstructed' and 'instrumental' ENSO series were standardised separately based on the years 1706-1879 (for which all indices are available) and 1880-2000, respectively. Thereafter, the Mann et al. (2000b) NINO3 index was merged with the corresponding instrumental (ERSST2) index from 1880 onwards. In order to define 'extreme' and 'strong' ENSO events, years outside \pm 2 or \pm 1 standard deviations in each ENSO index were marked. The selection of events was then based on the Cook (2000) index up to 1649 and on the merged Mann/ERSST2 index thereafter. From this selection we excluded those events prior to 1880 for which any of the other available indices or the list of El Niño events by Quinn and Neal (1992) indicates a strong ( \pm 1 standard deviations) ENSO event of opposite sign (see Fig. 1). Note that Quinn and Neal (1992) report more El Niño events in the sixteenth and seventeenth century than Ortlieb (2000). As a consequence, the number of La Niña cases in this period might be too low in our selection, but there is no effect on the selection of El Niño cases.
Events following major tropical volcanic eruptions were marked separately.

The reconstruction period was further subdivided into two periods. The first period (termed REC1) was defined as 1500 to 1705 and comprises 29 El Niño and 28 La Niña events. As only seasonal reconstructions are available for most of this period (1500-1658), the analysis was performed using the classical climatological seasonal means (SON, DJF, MAM). In this first period, the quality of all reconstructions (ENSO indices as well as climate field reconstructions in Europe) is reportedly low, which is also evident from comparing, for example, the two NINO3 indices from Mann et al. (2000b) and Cook (2000) in the overlapping period. In 1706, the Stahle et al. (1998) SOI data become available, and the agreement between the ENSO reconstructions is much better after that year. In the same year, several early instrumental series become available in Europe and the quality of the climate field reconstructions increases. The second subperiod REC2 covers the remaining reconstruction period, that is, 1706-1879. Twenty-two El Niños and 15 La Niñas fall into this period. Finally, the instrumental period (termed INS) extends from 1880 to 2005 and comprises 22 El Niño and 18 La Niña events.

Table 1 lists the selected events for all subperiods. In total, $73 \mathrm{El}$ Niño and $61 \mathrm{La}$ Niña situations were selected. Events following a major tropical volcanic eruption are marked separately. Note that this is the case for six El Niño events, but only one La Niña event. Two events at the beginning and ending of the period (La Niña 1500 and El Niño 2003) were omitted

Table 1 'Strong' El Niño and La Niña events from 1500 to 2003 in the three defined subperiods REC1 (1500-1705), REC2 (17061879) and INS (1880-2003)

\begin{tabular}{|c|c|c|c|}
\hline & REC1 & REC2 & INS \\
\hline El Niño & $\begin{array}{l}1511,1518,1519, \\
1520,1526,1530,1539, \\
1540,1550,1556,1586, \\
1594,1602^{\mathrm{a}}, 1610,1618, \\
1621,1639,1640,1652, \\
1657,1662,1666,1674^{\mathrm{a}}, \\
1675^{\mathrm{a}}, 1677,1681,1682, \\
1691,1702\end{array}$ & $\begin{array}{l}1718,1721,1723,1760,1767, \\
1784,1792,1793,1795,1800, \\
1804,1815,1816^{\mathrm{a}}, 1821,1829, \\
\frac{1833}{1869}, 1846,1852,1856, \\
1877, \underline{1878}\end{array}$ & $\begin{array}{l}\frac{1889,1897,1900,1903^{\mathrm{a}}, 1906,1912}{1915,1919,1926,1931,1940,1941} \\
1952,1958,1966, \underline{1973}_{197}, 1977, \underline{1983}^{\mathrm{a}} \\
1987,1992^{\mathrm{a}}, \underline{1998},{ }^{\mathrm{b}}\end{array}$ \\
\hline La Niña & $\begin{array}{l}1500^{\mathrm{b}}, 1506,1517,1522,1528, \\
1533,1538,1542,1573,1579 \\
1584,1593,1612,1613,1623, \\
1631,1637,1638,1645,1648, \\
1654,1664,1665,1672,1676, \\
1678,1698,1704\end{array}$ & $\begin{array}{l}1717, \underline{1725}, 1752,1757,1758 \\
\quad \frac{1790}{1822}, 1797,1835, \underline{1842}, \underline{1840} \\
1863,1872\end{array}$ & $\begin{array}{l}1887,1890,1893,1904^{\mathrm{a}}, 1910,1917,1925 \\
1934,1943,1950,1956,1968, \\
1971,1974,1976,1985,1989,2000\end{array}$ \\
\hline
\end{tabular}


in the following analysis as they might be affected by edge effects (this also holds for 1767 in the case of $500 \mathrm{hPa}$ GPH).

\subsection{Experimental design}

For extreme events in REC2 and INS (exceeding two standard deviations; underlined in Table 1) the anomaly fields were analysed individually. Then, composite fields were calculated within each period for strong El Niño and La Niña events. In contrast to the classical compositing technique that uses the arithmetic mean and a $t$-test for the means, we used a scaled mean and modified $t$-value as described by Brown and Hall (1999). This method gives more robust results if the distributions are not Gaussian or if there are outliers (see also Touchan et al. 2005; Pauling et al. 2006). The scaled mean $x_{\mathrm{s}}$ is tested against the null hypothesis $H_{0}$ : $\mu=0$.

To test the stationary behaviour of the relations between ENSO and European climate, we compared the results for the identified subperiods. In addition, we also analysed some of the most pronounced features in the form of time series. For this purpose we used the NAO index as well as early instrumental series that are close to corresponding anomaly centres. We tested the correlations of these series with the ENSO indices in a 51-year moving window against Monte Carlo simulations. This allows detecting a possible non-stationary behaviour at multidecadal scales. We also used the correlations between ENSO indices and the impact on European climate to address the modulating influences. For this purpose, we stratified the sample according to the supposed modulating factor (e.g. the sign of the PDO) and then tested whether the correlation coefficient is significantly different in the two strati using a Fisher's Z transformation followed by a Chi-square test.

When trying to address non-stationarities using climate reconstructions, a natural limitation has to be kept in mind. Both the reconstructions of El Niño (using predictors in the Pacific region) as well as the climate field reconstructions for Europe (using predictors from the North Atlantic-European area) are based on the assumption of stationarity. Hence, nonstationarities in the remote teleconnections can only be detected to the extent to which the local predictorpredictand relationships on which the reconstructions are based have remained stationary. Using early instrumental series in addition to climate reconstructions alleviates this constraint for the signal in Europe.

Finally, a multi-field clustering was performed for strong El Niño and La Nina events, respectively, from the combined periods REC 2 and INS. For this purpose, we performed principal component (PC) analyses separately on each field (i.e. variable) and sample, retaining enough PC to keep at least $90 \%$ of the variance. This corresponds to around three to five series in the temperature and SLP fields, but $10-15$ in the precipitation fields. Within each field and sample, the PC time series were divided by the standard deviation over all retained PC series and by the square root of the number of retained PC series. Then the PC time series from all fields were merged to obtain an El Niño and a La Niña sample. In this way each field contributes the same amount of information (Euclidian distance) to the clustering approach, while the differences in the variances of the PC within each field are retained. Clusters were obtained with the $k$-means technique employing the Hartigan and Wong (1979) algorithm. They were then again analysed using scaled means (Brown and Hall 1999) and modified $t$-values.

Most of the analyses were performed for all seasons and some for both a sample with and without volcanically perturbed years. For brevity's sake, we concentrate mainly on the late winter results and on the sample without volcanically perturbed years. We also addressed multidecadal variability by analysing the low-pass component of the filtered series. After subtracting a linear trend, regression analyses were performed using a NINO3 index and the reconstructed fields.

\section{Results and discussion}

\subsection{Extreme events}

Figure 2 shows January-to-March averaged anomaly fields of SLP, surface air temperature, European land precipitation and $500 \mathrm{hPa} \mathrm{GPH}$, together with corresponding early instrumental data, for the selected extreme events (outside two standard deviations). The most recent events $(1973,1983,1998)$ were omitted as they are well covered by other studies. For El Niño, the inter-event variability is relatively large. The winters of 1877 and 1889 were cold in northeastern Europe, but the other two were not. No consistent signal is found in precipitation, SLP or $500 \mathrm{hPa}$ GPH. For the La Niña winters, the inter-event variability is somewhat smaller. There is a tendency towards warm winters in northeastern Europe and a tendency for a strong Icelandic low. Four out of five cases show dry winters in central and western Europe. In both samples it is interesting that in the SLP and $500 \mathrm{hPa}$ GPH fields the main anomalies are often not congruent with the main cen- 

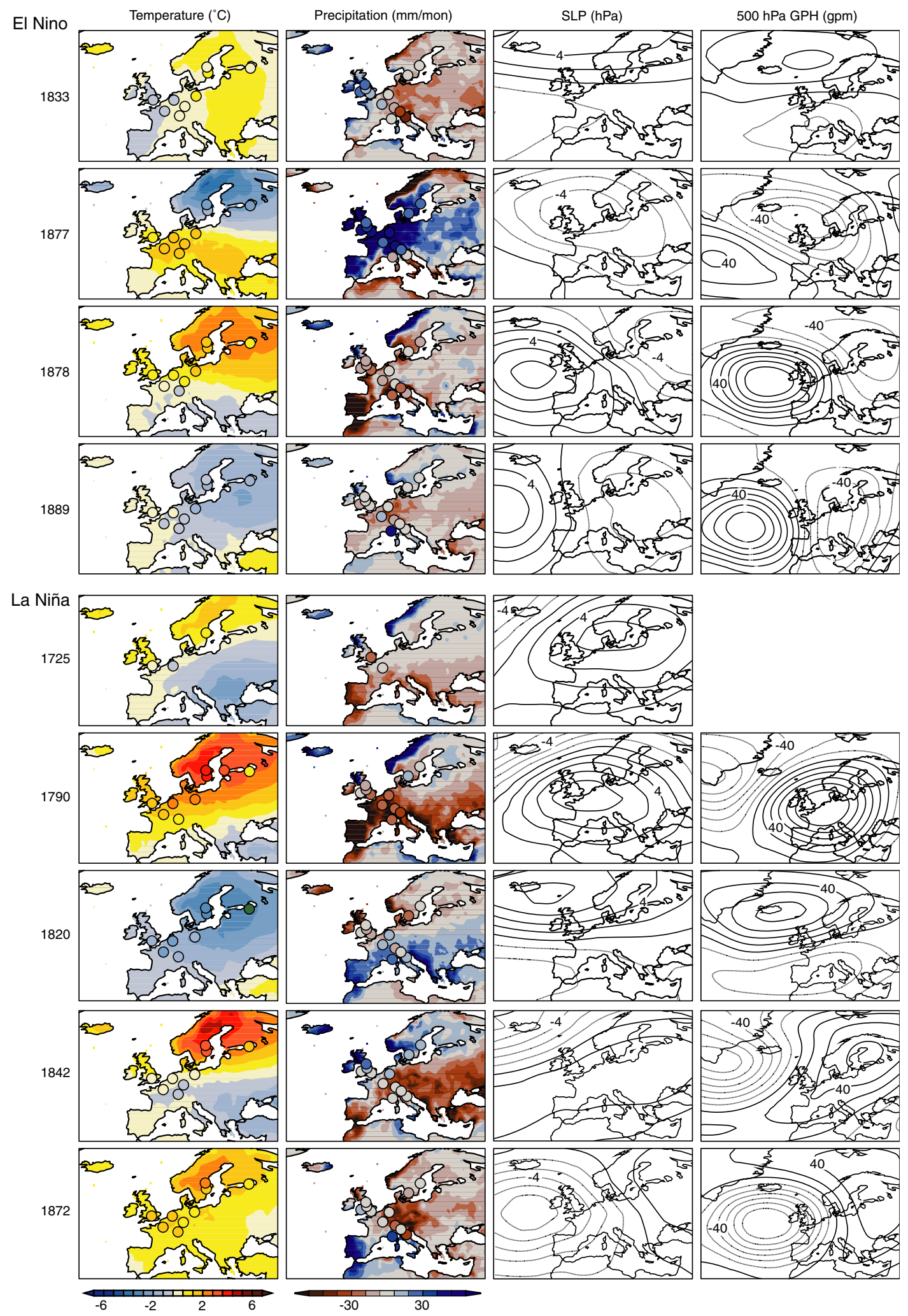

Fig. 2 High-pass filtered fields of temperature, precipitation, sea-level pressure $(S L P)$ and $500 \mathrm{hPa}$ geopotential height extreme El Niño and La Niña events in the eighteenth and $(G P H)$ in late winter (JFM; for precipitation DJF) during nineteenth centuries. Corresponding data from early instrumental records are given in circles 
tres of action. Rather, anomalies often appear off the coast of France.

Comparability of these results with the cases presented in Mann et al. (2000a) is limited, as the latter are for annual mean temperature. From both studies it is obvious that the inter-event variability is relatively large for extreme events. Note, however, that the uncertainty of the reconstructions adds to this variability. The reconstructed fields agree well with the early instrumental series, but the signal is slightly more consistent and inter-event variability is slightly smaller in the early instrumental data.

\subsection{Composites}

In the following, the strong ENSO events (outside one standard deviation) are studied. Figures 3-5 show the composites obtained for El Niño and La Niña (volcanically perturbed winters were excluded) for the three subperiods for fall, winter and spring. The El Niño patterns for late winter in period INS (1880-2000; Fig. 3) displays the expected 'canonical' signal. The main features in the SLP field are positive anomalies over Iceland and Scandinavia and negative anomalies west of Spain and over southern and central Europe. This pattern resembles the NAO pattern, but has stronger anomalies in eastern Europe. The $500 \mathrm{hPa}$ GPH field shows negative anomalies over Europe, though significant mainly over the central and northwestern part, probably reflecting frequent uppertrough situations. The temperature field reveals negative anomalies in northeastern Europe and positive in the Mediterranean region, especially in Turkey. Finally, precipitation was significantly higher at around $45^{\circ} \mathrm{N}$ and lower in northern Europe and the southern Mediterranean. The composite fields for period REC2 (1706-1879; Fig. 4) show a very similar pattern as for period INS (except for fall) but the scaled means are less significant for El Niño winters. The main features are also clearly confirmed when compositing early instrumental data (not shown). In both periods, the pattern persists into spring, though weaker and with the SLP pattern shifted northwards. In fall, the pattern in both periods (REC2 and INS) is different than in late winter in many respects. The SLP field shows negative anomalies south of Iceland. Precipitation anomalies in the southern Mediterranean area change sign from fall to spring. The seasonality of the El Niño signal found in REC2 and INS is in good agreement with results found by others (e.g. Xoplaki 2002; Mariotti et al. 2002; Moron and Plaut 2003).

The La Niña signal is close to symmetric to the El Niño signal during period INS, most notably in winter, but to a lesser extent also in spring and fall. Symmetry is also found in winter in period REC2 (here the La Niña signal is even more pronounced than in INS). Interestingly, in period INS the most important features are clearly less significant for the La Niña case than for the El Niño composite.

For period REC1 (1500-1705, Fig. 5), significance is very limited, which might be due to uncertainties in both ENSO and the European climate field reconstructions. Above normal temperatures in northern Europe are found during El Niño winters and La Niña springs, and precipitation is above normal in the St. Petersburg region during La Niña. These features differ from the results found in later periods. For the case of temperature, this could partly be due to the different definitions of the seasons. However, a non-stationary behaviour cannot be ruled out and improved reconstructions have to be awaited in order to be able to better address this time period (unfortunately, there are too few early observational records to analyse this period). For this reason and because of the different definitions of the seasons, REC1 is not used in the following analyses, in which the data from the other two periods are pooled.

Recall that for REC2 and INS, we found a close to symmetric signal for El Niño and La Niña in the composites' scaled means. However, a non-linearity may show up in the higher moments of the frequency distribution. We therefore analysed the distribution functions of several variables for $\mathrm{El} \mathrm{Niño} \mathrm{and} \mathrm{La}$ Niña events in the form of histograms. For this analysis we used two early instrumental records that are close to the main anomaly centres, that is, temperature in Uppsala (since 1722), and precipitation in Paris (since 1706). In addition, we analysed the NAO index. Figure 6 shows histograms for these three series for strong El Niño and strong La Niña (outside one standard deviation, volcanic eruptions were excluded) since 1706. There is a clear signal in the mean and median, as expected from the composite analysis. The standard deviation is smaller for $\mathrm{El}$ Niño than for La Niña for temperature at Uppsala and for the NAO index. This result contrasts to some extent with the studied extreme events (Sect. 3.1), where a large inter-event variability was found for El Niño. It also contrasts with other studies as it is generally assumed (e.g. Pozo-Vázquez et al. 2001, 2005; Gouirand and Moron 2003; Alpert et al. 2006) that the La Niña signal is more robust than the El Niño signal. One major difference between this study and others is the exclusion of volcanically perturbed years (implications will be further addressed in Sect. $3.3)$. 

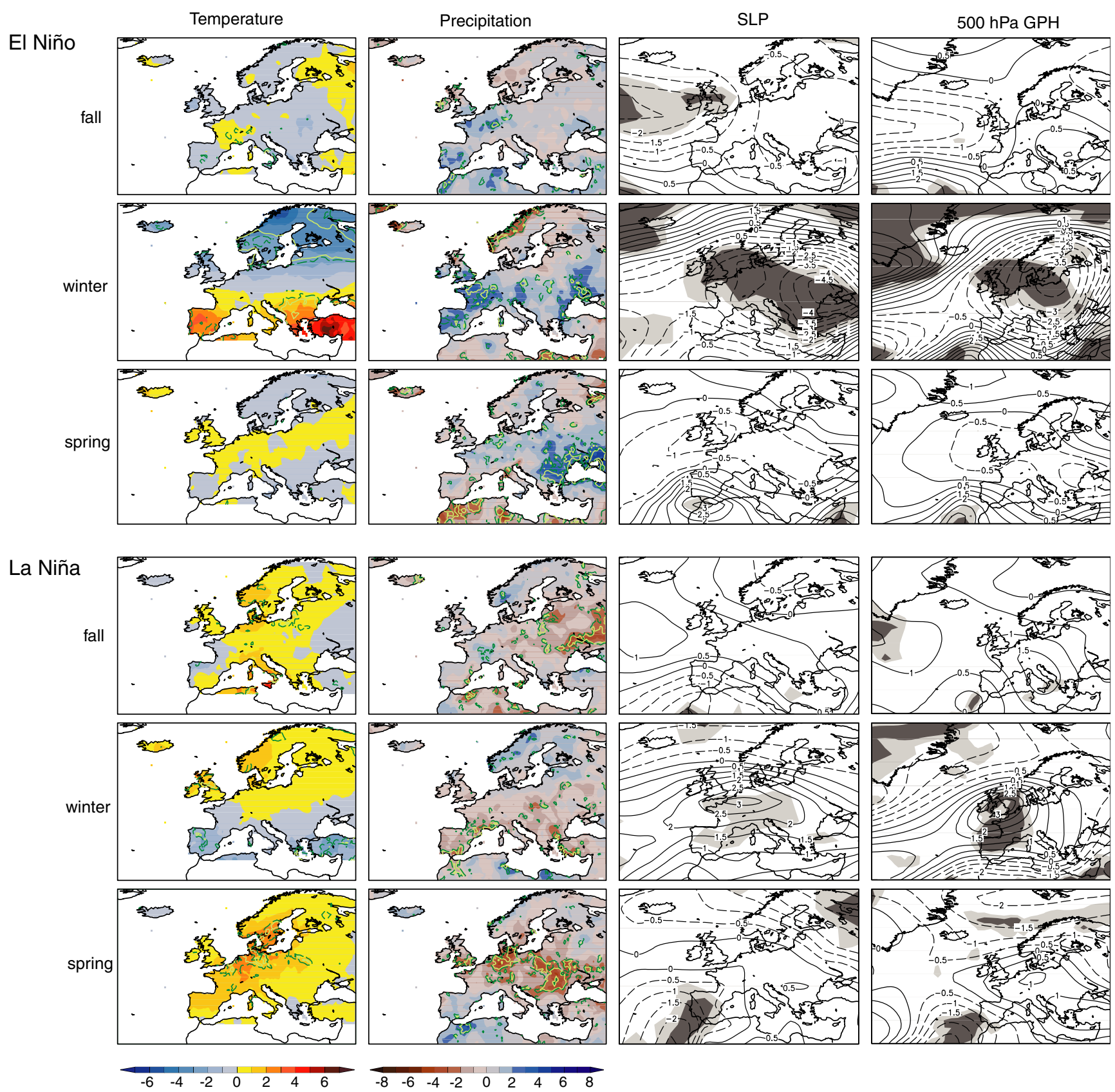

Fig. 3 Composite anomaly fields (scaled means, modified $t$ values; see text for details) of temperature, precipitation, sealevel pressure $(S L P)$ and $500 \mathrm{hPa}$ geopotential height $(G P H)$ for different seasons during strong El Niño and La Niña events in the period INS (1880-2003, volcanically perturbed winters were excluded). Note that fall, winter and spring refer to OND, JFM and AMJ for temperature, SLP and $500 \mathrm{hPa}$ GPH, but to SON, DJF and MAM for precipitation. Units are arbitrary. Shadings for SLP and $500 \mathrm{hPa}$ GPH as well as the dashed dark green and solid light green contours (temperature and precipitation) indicate significance at the $95 \%$ and $99 \%$ confidence levels

Niño than for strong La Niña events. Very dry winters occur with equal probability during both ENSO phases, but very wet winters are more frequent during El Niño. In all three cases, including volcanic eruptions would not only lead to smaller differences of the mean values, but also to smaller differences in the standard deviations.
The number of cases is too small for statistically addressing the shape of the distributions. However, it is interesting to look at the extremes of the distributions. Very cold winters in Uppsala during La Niña, though relatively rare, are more frequent than very warm winters during El Niño. For precipitation in Paris the standard deviation is higher for strong $\mathrm{El}$ 

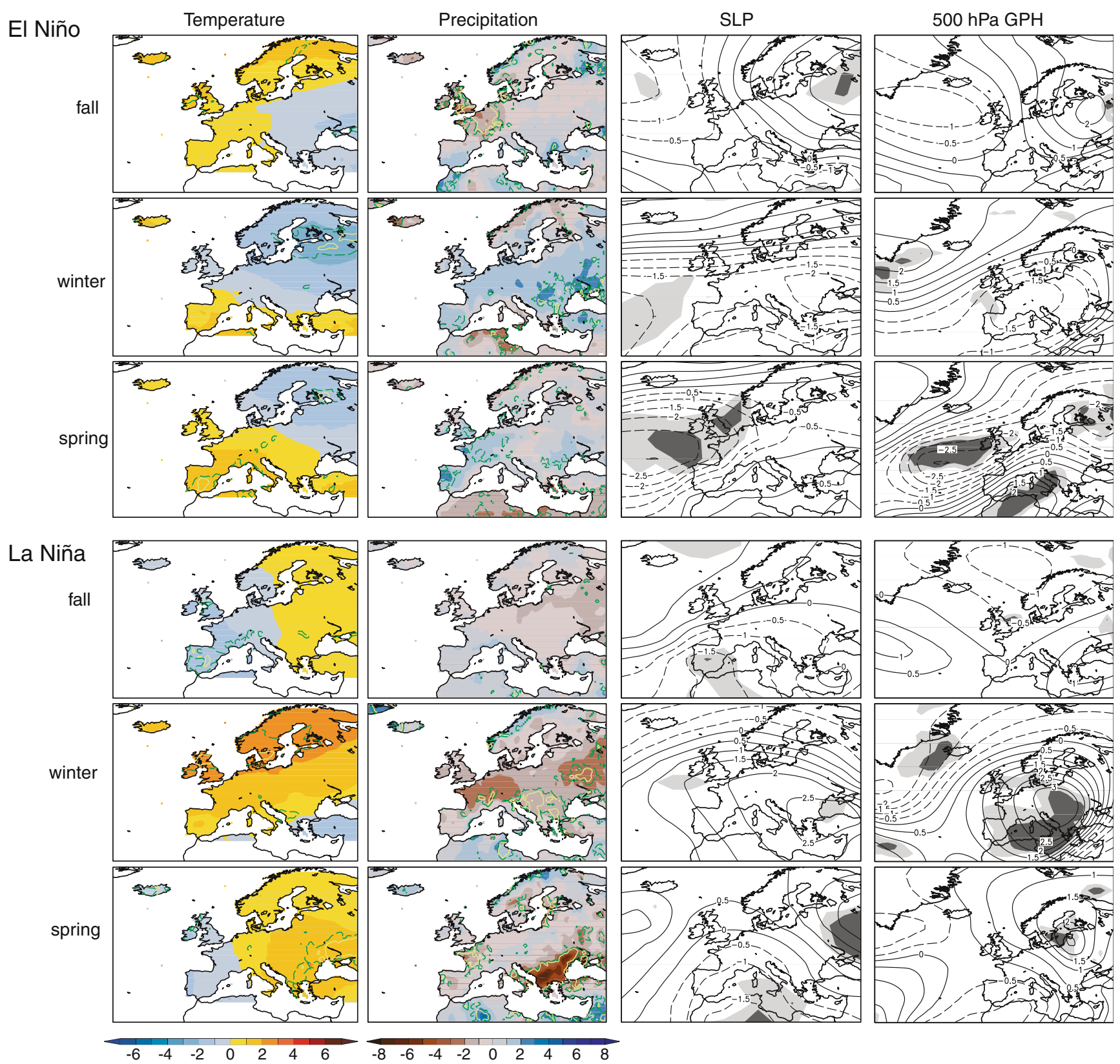

Fig. 4 Composite anomaly fields (scaled means, modified $t$ values; see text for details) of temperature, precipitation, sealevel pressure $(S L P)$ and $500 \mathrm{hPa}$ geopotential height $(G P H)$ for different seasons during strong El Niño and La Niña events in the period REC2 (1706-1879, volcanically perturbed winters were excluded). Note that fall, winter and spring refer to OND,

\subsection{Moving correlations}

The composites shown in Fig. 3-5 reveal similar anomaly patterns for all subperiods (especially REC2 and INS). From this analysis, we find no evidence for a non-stationary relation between ENSO and European climate. However, the subperiods are long and may not be well suited for detecting non-stationary behaviour.
JFM and AMJ for temperature, SLP and $500 \mathrm{hPa}$ GPH, but to SON, DJF and MAM for precipitation. Units are arbitrary. Shadings for SLP and $500 \mathrm{hPa}$ GPH as well as the dashed dark green and solid light green contours (temperature and precipitation) indicate significance at the $95 \%$ and $99 \%$ confidence levels

To test this further we analysed 51-year moving correlations between the filtered and standardised Mann/ ERSST2 NINO3 index (thick lines in bottom part of Fig. 1), from which volcanically perturbed winters were excluded, and the three series discussed earlier (temperature Uppsala, precipitation Paris, NAO index). The sign was changed such as to obtain positive correlation for all series, that is, we used the negative 

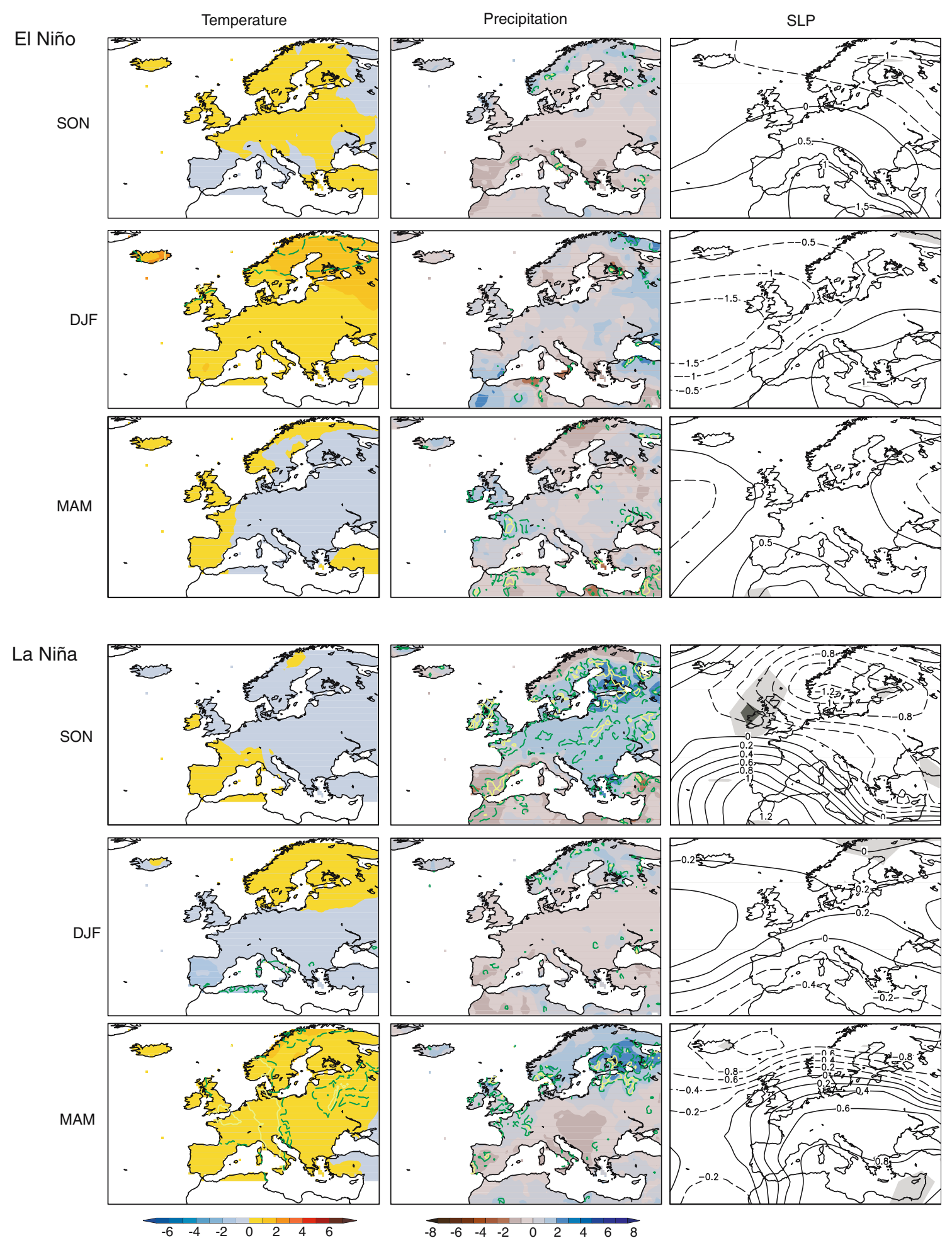

Fig. 5 Composite anomaly fields (scaled means, modified $t$ values; see text for details) of temperature, precipitation and SLP, for different seasons during strong El Niño and La Niña events in the period REC1 (1500-1705, volcanically perturbed winters were excluded). Units are arbitrary. Shadings for SLP as well as the dashed dark green and solid light green contours (temperature and precipitation) indicate significance at the $95 \%$ and $99 \%$ confidence levels 


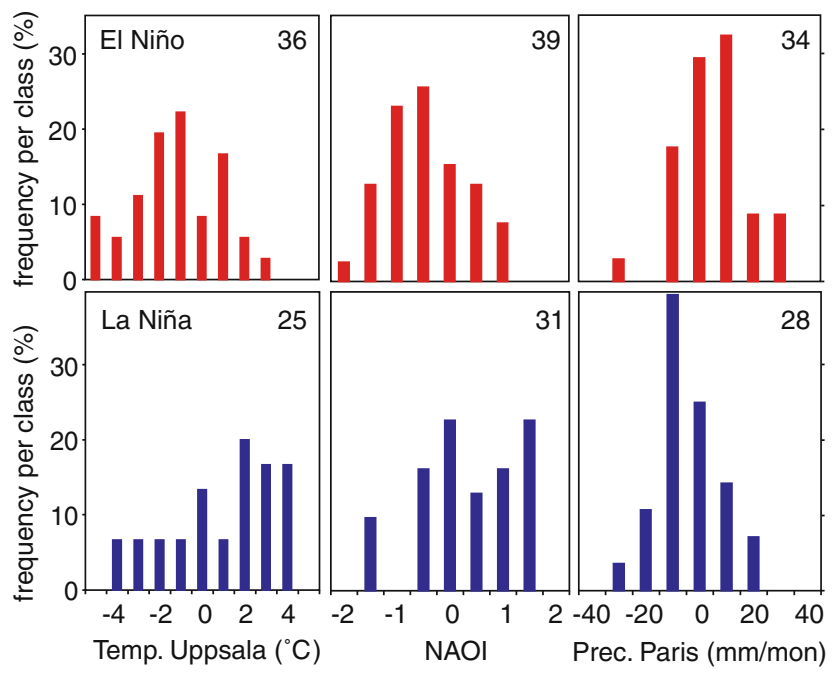

Fig. 6 Histograms of January-to-March averages of temperature at Uppsala (left, since 1722), the North Atlantic Oscillation $(N A O)$ index (middle, 1706) and precipitation in Paris (right, 1706) for strong El Niño events (top, red) and strong La Niña events (bottom, blue). Volcanically perturbed winters were excluded. The number of cases is given in the top right corner

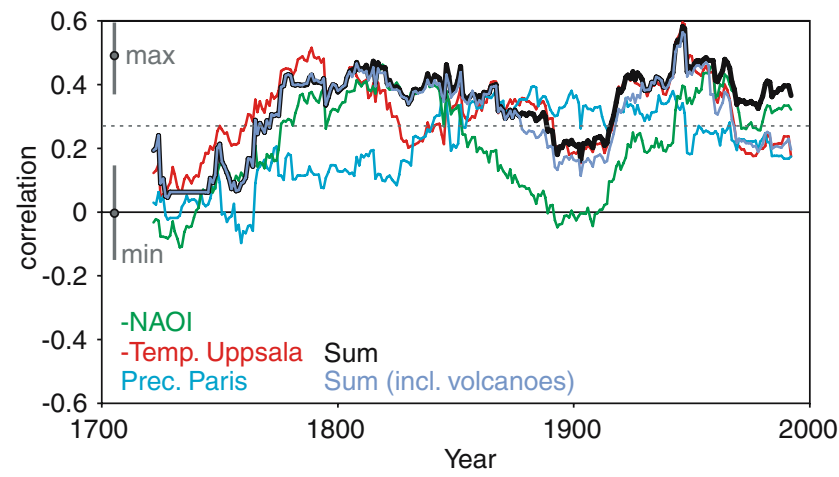

Fig. 7 Coefficients of the correlation between the Mann et al. (2000b) NINO3 index (updated with ERSST2 after 1879) and several series that describe the expected response of European climate (January-to-March averages of the negative temperature at Uppsala, the negative North Atlantic Oscillation (NAO) index, precipitation in Paris, as well as the sum of the three standardised series) in a 51-year moving window. Volcanically perturbed winters were excluded except for the grey line. The dashed line shows the critical value of the correlation coefficient for a single correlation $(0.27, P=0.05)$, ' $m a x$ ' and 'min' give the estimated maxima and minima plus their $95 \%$ confidence intervals obtained from Monte Carlo simulations, assuming a correlation of 0.27 over the whole period

temperature at Uppsala, precipitation in Paris, and the negative NAO index. In order to obtain a measure of the 'canonical' effect, we defined a new index SUM as the sum of the three standardised series. The moving correlations are shown in Fig. 7, together with the significance limit for an individual correlation as well as estimates and $95 \%$ confidence intervals for the maxima and minima in the time series of correlation coefficients, determined from Monte Carlo simulations (assuming a correlation coefficient of 0.27 over the whole period). All of the series show a positive correlation with NINO3 almost throughout the period. However, correlations are not strong as they vary between -0.1 and 0.6, approximately. Correlations are generally highest in the late eighteenth and in the midtwentieth century. For SUM they are almost always above the significance limit (for an individual coefficient) after around 1765 . The minima and maxima in each time series of correlation coefficients are in very good agreement with the corresponding Monte Carlo estimations. In all, this moving correlation analysis not only confirms again that there is an ENSO effect on Europe, but also that the relationship between these European surface climate indices and ENSO has not changed much over time. Statistically, there is no evidence for a non-stationary behaviour of the influence of ENSO on European climate throughout the last 280 years. However, at the Earth's surface the correlations are relatively modest.

When volcanic eruptions are not removed from the NINO3 index (grey line in Fig. 7), correlations tend to be lower. They even drop to insignificant values in the past 50 years, which is the time period on which many analyses of ENSO effects on Europe are based (e.g. Greatbatch et al. 2004). This effect is expected, as volcanic eruptions tend to concur with El Niño events, but have an opposite effect. It is therefore argued that volcanic eruptions should be excluded from an analysis of ENSO effects in Europe.

\subsection{Modulating factors}

The correlations between surface climate and ENSO are relatively low (see Fig. 7). While this can to some extent be explained by the large internal variability of the atmospheric circulation in the extratropics (and its random interaction with ENSO), it is also possible that the ENSO signal is systematically modulated by other, potentially predictable influences. To address this point we stratified the relationship between NINO3 and SUM indices (volcanic eruptions were excluded) according to possible modulating factors. Thereby we distinguished between a modulation on the interannual scale (stratifying according to the sign of the anomalies of the modulating factor) and a modulation of interannual variability on the decadal scale (according to the sign of the low-pass component of the modulating factor with respect to 1961-1990).

For the influence of the North Pacific, we used five time series: two PDO reconstructions, the Gulf of 

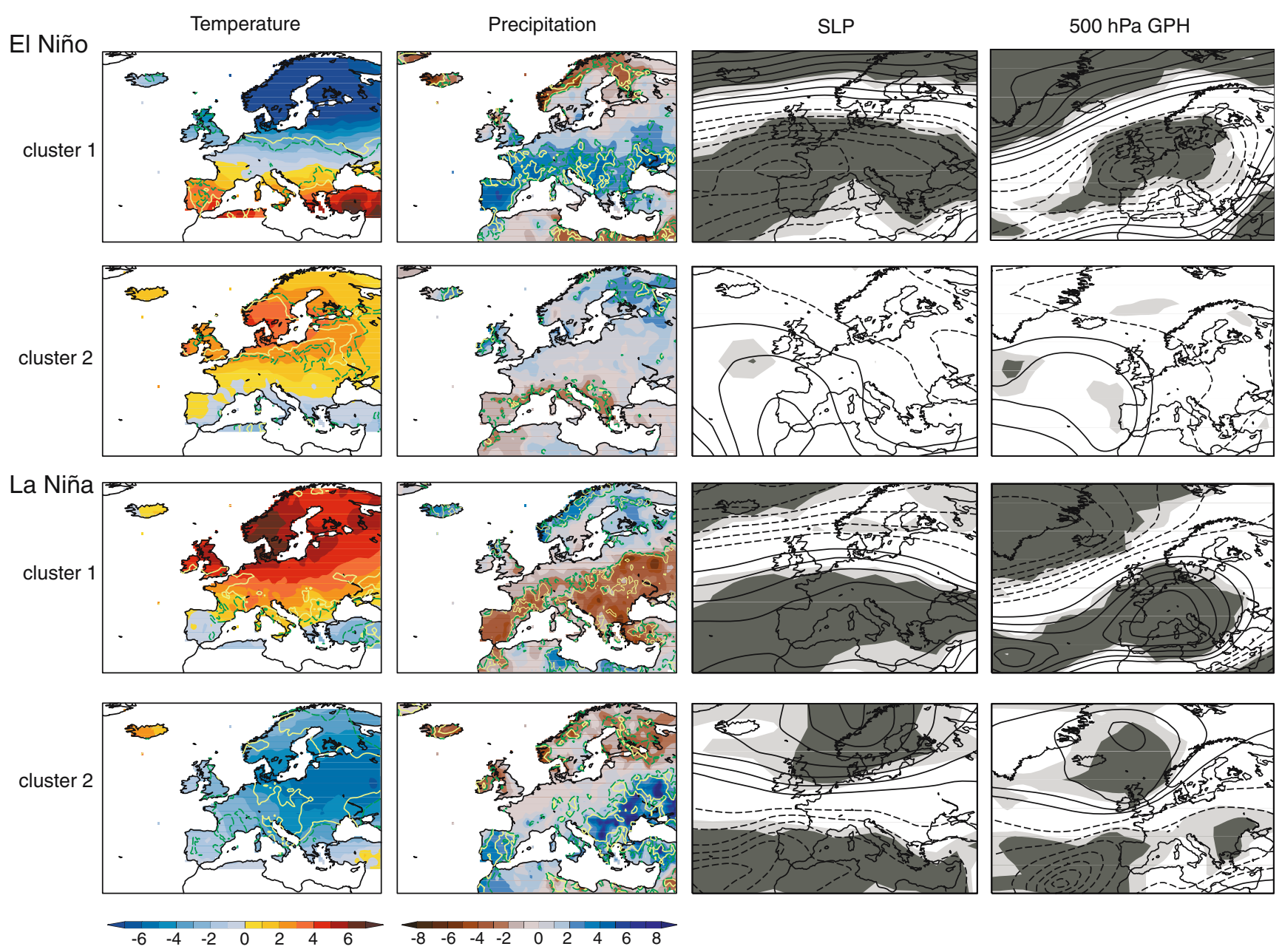

Fig. 8 Composite anomaly fields (scaled means, modified $t$ values; see text for details) of temperature, precipitation, sealevel pressure $(S L P)$ and $500 \mathrm{hPa}$ geopotential height $(G P H)$ in late winter for clusters 1 and 2 of a two cluster solution for strong El Niño (top) and La Niña (bottom) events in the periods REC1 and INS (1706-2000, volcanically perturbed winters were

excluded). Note that late winter refers to JFM except for precipitation (DJF). Units are arbitrary. Zero contours are not shown for SLP and $500 \mathrm{hPa}$ GPH. Shadings for SLP and $500 \mathrm{hPa}$ GPH as well as the dashed dark green and solid light green contours (temperature and precipitation) indicate significance at the $95 \%$ and $99 \%$ confidence levels

Alaska temperature in April to September, and Mt. Logan snow accumulation and oxygen isotope records (see Sect. 2.4). For the interannual modulation we found higher correlations between NINO3 and SUM when the North Pacific time series in the year prior to the analysed winter was in phase with ENSO compared to when they were out of phase. The differences in the correlation coefficients were significant for the two of the three PDO indices [corresponding $p$-values are $0.01,0.03$ and 0.10 for the D'Arrigo et al. (2001), Biondi et al. (1998) and Shen et al. (2006) indices, respectively]. The PDO anomalies are assumed to largely represent ENSO forcing plus stochastic forcing from the extratropical atmosphere, modified and damped by oceanic processes (see also Newman et al. 2003). Note also that PDO and ENSO reconstructions might be dependent. Hence, the results do not make clear whether it is the North Pacific ocean that exerts a modulating influence or whether the North Pacific merely reflects differences in the tropical signal during the previous year (e.g. the onset phase of ENSO). The results do show, however, that when the ENSO signal in the North Pacific area does not follow the 'classical' pattern (which involves a positive PDO index), then the signal in Europe also tends to be weaker or different. Since we used the PDO index of the previous year, this indicates potential predictability. No modulation was found for the decadal scale.

For possible modulations in the North Atlantic area, we tested September-to-December averages of the NAOI as well as basin-wide $\left(0-70^{\circ} \mathrm{N}\right)$ SST anomalies. In both cases we tested a modulation of the amplitude 
(stratification by sign of modulating factor) and a modulation of the sign (stratification by in-phase or out-of-phase relationship with NINO3). No significant modulating effects were found, neither on the interannual scale, nor on the decadal scale. Unfortunately, no spatially resolved SST reconstructions are available, which could provide more useful results.

\subsection{Clustering}

Related to the question of a modulation of the signal is the question whether or not there are several distinct, robust effects of ENSO on European climate. These different signals might be distinguishable using a cluster analysis. In a simple two-cluster case, for example, one might find a symmetric response and an asymmetric response. If ENSO can affect Europe both via the North Pacific area and via the tropical Atlantic, one might detect an 'ENSO-North Pacific' signal and an 'ENSO-tropical Atlantic' signal. As described in Sect. 2, we performed a multi-field (temperature, SLP and precipitation in late winter, volcanically perturbed winters removed) clustering analysis for strong El Niño and strong La Niña events in the periods REC2 and INS combined. The selection encompasses 39 and 32 strong events, respectively. As theory does not provide an optimal number of clusters, we started with two clusters and then increased the number of clusters to three and four.

Independent of the number of clusters, one cluster (here denoted cluster 1) is always much larger than the

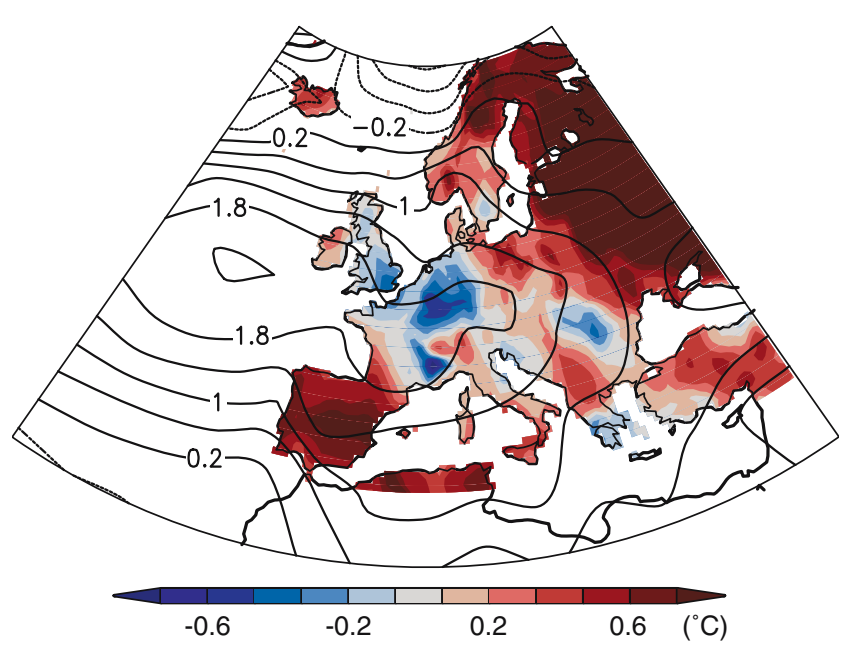

Fig. 9 Coefficients of a regression between the Mann et al. (2000b) NINO3 index and fields of temperature and sea-level pressure $(S L P)$ over Europe in late winter (JFM) for the periods 1706-2000 (REC2 and INS, volcanically perturbed winters were excluded) after a low-pass filtering and detrending procedure other ones and exhibits the 'canonical signal'. We analyse here only the two-cluster solution, as in the other solutions the cluster sizes become very small. Figure 8 shows composite fields for the two-cluster approach. For cluster 1, which comprises 26 out of 39 El Niño events and 25 out of 32 La Niña events, results are very clear and highly significant. The symmetry of the signal for El Niño and La Niña is striking. Results also compare very well with a similar cluster analysis (based only on SLP) performed by Gouirand and Moron (2003). The cluster 2 shows a meridional circulation anomaly pattern for El Niño but a zonal pattern for La Niña. Hence, the two clusters are not symmetric to each other. Cluster 2, though limited in size, might contribute (in addition to the volcanic eruptions) to the non-linear signal found by some authors.

In order to test whether the two clusters could stem from a modulation of the signal, we compared the mean values of corresponding indices between the clusters. No significant differences were found except for the basin-wide temperature anomaly of the Atlantic Ocean in the year before the analysed event in the case of the El Niño clusters. Here, cluster 1 events tend to be preceded by negative Atlantic SST anomalies and cluster 2 events by positive anomalies.

\subsection{Low-frequency variability}

In all previous analyses we have only addressed the interannual variability and have removed the decadal variability. In this section we would like to look specifically at the decadal to multidecadal component. With respect to ENSO, this means that we are focussing on 'ENSO-like' variability that is sometimes referred to as Interdecadal Pacific Oscillation (Folland et al. 2002). We omitted volcanic eruptions, removed a linear trend from all series and then regressed the reconstructed fields onto the NINO3 index. Figure 9 shows the result for temperature and SLP in late winter (REC2 and INS).

Clearly, the signal is very different than on the interannual scale. In fact, it is close to opposite, with positive temperature anomalies over northeastern Europe and a positive NAO index. This is surprising at first, but is in excellent agreement with what was found by Mann et al. (2000a) for the multidecadal variability in annual mean fields. No explanation for these results can be given at the moment. More research, especially analyses of coupled model simulations, is clearly needed to address multidecadal ENSO variability (e.g. Mann et al. 2000a, 2005) and its effect on European climate. 


\section{Conclusions}

In this paper we have addressed the relation between ENSO and atmospheric circulation and climate in the North Atlantic-European area based on statistically reconstructed ENSO indices, long instrumental series, and reconstructed fields of temperature, SLP, precipitation and $500 \mathrm{hPa}$ GPH covering the past 250 500 years. This allows to significantly expand the time scale compared to most other studies on ENSO effects in Europe that are based on data from the late nineteenth and twentieth century. The results for the eighteenth and nineteenth centuries (after excluding volcanically perturbed years) are very similar to those found by other authors for the twentieth century. They show the 'canonical' late winter signal with (for El Niño) negative and positive temperature anomalies in northeastern Europe and Turkey, respectively, a negative NAO, frequent upper troughs over central Europe, and positive and negative precipitation anomalies around $45^{\circ} \mathrm{N}$ and in Norway and the southeastern Mediterranean area, respectively. They also reveal the reported seasonal differences in the effect between early winter and late winter or spring and they show a close to symmetric response for $\mathrm{La}$ Niña in most respects. Unlike other studies (none of which excludes volcanically perturbed winters), we find a very similar amount of inter-event variability for El Niño and La Niña with respect to the main features. In all, we find a consistent (though rather weak), stationary signal during the past 300 years, whereas no clear conclusions can be made for the sixteenth and seventeenth centuries.

However, not all ENSO events are accompanied by the anomalies reported earlier. In order to narrow down the causes for the relatively large inter-event variability, we addressed possible modulating factors and performed a cluster analysis. We find that the signal in Europe is strong when the climate in the North Pacific (as measured by the PDO index in the year prior to the analysed ENSO winter) is in phase with ENSO. This is in agreement with our current understanding of the mechanisms of ENSO effects on European climate, which involve a downstream propagation of the tropical disturbance from the $\mathrm{Pa}$ cific sector to the North Atlantic (e.g. Fraedrich 1994). Our analyses also show that it is very important to remove volcanically perturbed winters when analysing ENSO effects on European climate. This is especially true for the last 50 years. In all, our results suggest that ENSO could potentially be a source of seasonal prediction skill for the North AtlanticEuropean sector.
Acknowledgments S.B. was funded by the Swiss National Science Foundation. J.L. and E.X. were funded by the Swiss National Competence Center for Research in Climate. C.C. is funded by the Fifth European framework programme, project PACLIVA (EVRI-2002-000413). E.X. and A.P. were also financially supported through the European Environment and Sustainable Development programme project SOAP (EVK2CT-2002-00160). Additionally, E.X. was supported through the European Environment and Sustainable Development programme, project EMULATE (EVK2-CT-2002-00161).

\section{References}

Adams JB, Mann ME, Ammann CM (2003) Proxy evidence for an El Niño-like response to volcanic forcing. Nature 426:274-278

Alpert P et al. (2006) Relations between climate variability in the Mediterranean region and the Tropics: ENSO, South Asian and African Monsoons, Hurricanes and Saharan dust. In: Lionello P, Malanotte-Rizzoli P, Boscolo R (eds) The Mediterranean climate: an overview of the main characteristics and issues, Elsevier, pp 149-177

Ammann CM, Naveau P (2003) Statistical analysis of tropical explosive volcanism occurrences over the last 6 centuries, Geophys Res Lett 30. DOI 10.1029/2002GL016388

Bergström H, Moberg A (2002) Daily air temperature and pressure series for Uppsala (1722-1998). Clim Change 53:213-252

Biondi F, Gershunov A, Cayan DR (2001) North Pacific decadal climate variability since AD 1661. J Clim 14:5-10

Brázdil R, Pfister C, Wanner H, von Storch H, Luterbacher J (2005) Historical climatology in Europe-the state of the art. Clim Change 70:363-430

Brönnimann S, Luterbacher J (2004) Reconstructing northern hemisphere upper-level fields during World War II. Clim Dyn 22:499-510

Brönnimann S, Luterbacher J, Staehelin J, Svendby TM, Hansen G, Svenøe T (2004) Extreme climate of the global troposphere and stratosphere 1940-1942 related to El Niño. Nature 431:971-974

Brown TJ, Hall BL (1999) The use of $t$ values in climatological composite analyses. J Clim 12:2941-2945

Casty C, Handorf D, Sempf M (2005) Combined winter climate regimes over the North Atlantic/European sector 17662000. Geophys Res Lett 32. DOI 10.1029/2005GL022431

Cook ER (2000) Nino 3 Index Reconstruction. International Tree-Ring Data Bank. IGBP PAGES/World Data CenterA for Paleoclimatology. Data Contribution Series \#2000052. NOAA/NGDC Paleoclimatology Program, Boulder, CO, USA

D'Arrigo R, Villalba R, Wiles G (2001) Tree-ring estimates of Pacific decadal climate variability. Clim Dyn 18:219-224

D'Arrigo R, Cook E, Wilson R, Allan R, Mann M (2005a) On the variability of ENSO over the past six centuries. Geophys Res Lett 32. DOI 10.1029/2004GL022055

D'Arrigo R, Wilson R, Deser C, Wiles G, Cook E, Villaba R, Tudhop A, Cole J, Linsley B (2005b) Tropical-North Pacific climate linkages over the past four centuries. J Clim 18:5253-5365

Felis T, Pätzold J, Loya Y, Fine M, Nawar AH, Wefer G (2000) A coral oxygen isotope record from the northern Red Sea documenting NAO, ENSO, and North Pacific teleconnections on Middle East climate variability since the year 1750. Paleoceanography 15:679-694 
Fischer E, Luterbacher J, Zorita E, Tett SFB, Casty C, Wanner $\mathrm{H}$ (submitted) European climate response to major volcanic eruptions for the last half millennium

Folland CK, Renwick JA, Salinger MJ, Mullan AB (2002) Relative influences of the interdacadal Pacific oscillation and ENSO on the South Pacific convergence zone. Geophys Res Lett 29. DOI 10.1029/2001GL014201

Fraedrich K (1994) ENSO Impact on Europe?—a review. Tellus 46A:541-552

Fraedrich K, Müller K (1992) Climate anomalies in Europe associated with ENSO extremes. Int J Climatol 12:25-31

Gouirand I, Moron V (2003) Variability of the impact of El Niño-southern oscillation on sea-level pressure anomalies over the North Atlantic in January to March (1874-1996). Int J Climatol 23:1549-1566

Gray ST, Graumlich LJ, Betancourt JL, Pederson GD (2004) A tree-ring based reconstruction of the Atlantic multidecadal oscillation since 1567 A.D. Geophys Res Lett 31. DOI 10.1029/2004GL019932

Greatbatch RJ, Lu J, Peterson KA (2004) Nonstationary impact of ENSO on Euro-Atlantic winter climate. Geophys Res Lett 31. DOI 10.1029/2003GL018542

Hartigan JA, Wong MA (1979) A $k$-means clustering algorithm. J Roy Stat Soc C-App 28:100-108

Kalnay E, et al. (1996) The NCEP/NCAR 40-year reanalysis project. Bull Am Meteorol Soc 77:437-471

Kistler R, et al. (2001) The NCEP-NCAR 50-year reanalysis: monthly means CD-ROM and documentation. Bull Am Meteorol Soc 82:247-267

Knippertz P, Ulbrich U, Marques F, Corte-Real J (2003) Decadal changes in the link between El Niño and springtime North Atlantic oscillation and European-North African rainfall. Int J Climatol 23:1293-1311

Luterbacher J, Dietrich D, Xoplaki E, Grosjean M, Waner H (2004) European seasonal and annual temperature variability, trends, and extremes since 1500. Science 303:1499-1503

Luterbacher J, Xoplaki E, Dietrich D, Rickli R, Jacobeit J, Beck C, Gyalistras D, Schmutz C, Wanner H (2002a) Reconstruction of sea-level pressure fields over the eastern North Atlantic and Europe back to 1500. Clim Dyn 18:545-561

Luterbacher J, Xoplaki E, Dietrich D, Jones PD, Davies TD, Portis D, Gonzalez-Rouco JF, von Storch H, Gyalistras D, Casty C, Wanner H (2002b) Extending North Atlantic oscillation reconstructions back to 1500 . Atmos Sci Lett 2:114-124

Mann ME, Bradley RS, Hughes MK (2000a) Long-term variability in the El Nino southern oscillation and associated teleconnections. In: Diaz HF, Markgraf V (eds) El Nino and the southern oscillation: multiscale variability and its impacts on natural ecosystems and society, Cambridge University Press, pp 321-372

Mann ME, Gille EP, Bradley RS, Hughes MK, Overpeck JT, Keimig FT, Gross WS (2000b) Global temperature patterns in past centuries: an interactive presentation. Earth Interact 4:1-29

Mann ME, Cane MA, Zebiak SE, Clement A (2005) Volcanic and solar forcing of the tropical Pacific over the past 1000 years. J Clim 18:447-456

Mantua NJ, Hare SR, Zhang Y, Wallace JM, Francis RC (1997) A Pacific interdecadal oscillation with impacts on salmon production. Bull Am Meteorol Soc 78:1069-1079

Mariotti A, Ballabrera-Poy J, Zeng N (2005) Tropical influence on Euro-Asian autumn rainfall variability. Clim Dyn 24:511-521
Mariotti A, Zeng N, Lau K-M (2002) Euro-Mediterranean rainfall and ENSO-a seasonally varying relationship. Geophys Res Lett 29. DOI 10.1029/2001GL014248

Mathieu PP, Sutton RT, Dong BW, Collins M (2004) Predictability of winter climate over the North Atlantic European region during ENSO events. J Clim 17:1953-1974

Merkel U, Latif M (2002) A high resolution AGCM study of the El Niño impact on the North Atlantic/European sector. Geophys Res Lett 29. DOI 10.1029/2001GL013726

Mitchell TD, Jones PD (2005) An improved method of constructing a database of monthly climate observations and associated high-resolution grids. Int J Climatol 25:693-712

Moore GWK, Holdsworth G, Alverson K (2002) Climate change in the North Pacific region over the past three centuries. Nature 420:401-403

Moron M, Gouirand I (2003) Seasonal modulation of the ENSO relationship with sea level pressure anomalies over the North Atlantic in October-March 1873-1996. Int J Climatol 23:143-155

Moron M, Plaut G (2003) The impact of El Niño southern oscillation upon weather regimes over Europe and the North Atlantic boreal winter. Int J Climatol 23:363-379

Newman M, Compo G, Alexander MA (2003) ENSO-forced variability of the Pacific decadal oscillation. J Clim 16:38533857

van Oldenborgh GJ (2005) Comment on 'predictability of winter climate over the North Atlantic European region during ENSO events' by P.-P. Mathieu, R. T. Sutton, B. Dong and M. Collins. J Clim 18:2770-2772

van Oldenborgh GJ, Burgers G (2005) Searching for decadal variations in ENSO precipitation teleconnections. Geophys Res Lett 32. DOI 10.1029/2005GL023110

Ortlieb L (2000) The documentary historical record of El Niño events in Peru: an update of the Quinn record (sixteenth through nineteenth centuries). In: Diaz H, Markgraf V (eds) El Niño and the southern oscillation: variability, global and regional impacts, Cambridge University Press, pp207-295

Pauling A, Luterbacher J, Casty C, Wanner H (2006) Five hundred years of gridded high-resolution precipitation reconstructions over Europe and the connection to largescale circulation. Clim Dyn 26:387-405

Pozo-Vázquez D, Esteban-Parra MJ, Rodrigo FS, Castro-Diez Y (2001) The association between ENSO and winter atmospheric circulation and temperature in the North Atlantic region. J Clim 14:3408-3420

Pozo-Vázquez D, Gámiz-Fortis SR, Tovar-Pescador J, EstebanParra MJ, Castro-Díez Y (2005) North Atlantic winter SLP anomalies based on the autumn ENSO state. J Clim 18:97103

Quinn WH, Neal VT (1992) The historical record of El Niño events. In: Bradley RS, Jones PD (eds) Climate since AD 1500, Routledge, London, pp 623-648

Raible CC, Luksch U, Fraedrich K (2004) Precipitation and northern hemisphere regimes. Atmos Sci Lett 5:43-55

Rimbu N, Lohmann G, Felis T, Patzold J (2003) Shift in ENSO teleconnections recorded by a northern Red Sea coral. J Clim 16:1414-1422

Robock A (2000) Volcanic eruptions and climate. Rev Geophys 38:191-219

Schmutz C, Gyalistras D, Luterbacher J, Wanner H (2001) Reconstruction of monthly 700, 500 and $300 \mathrm{hPa}$ geopotential height fields in the European and Eastern North Atlantic region for the period 1901-1947. Clim Res 18:81193 
Shen C, Wang WC, Gong W, Hao Z (2006) A Pacific decadal oscillation record since $1470 \mathrm{AD}$ reconstructed from proxy data of summer rainfall over eastern China. Geophys Res Lett 33. DOI 10.1029/2005GL024804

Slonosky VC (2002) Wet winters, dry summers? Three centuries of precipitation data from Paris. Geophys Res Lett 29:18951898

Smith TM, Reynolds RW (2004) Improved extended reconstruction of SST (1854-1997). J Clim 17:2466-2477

Stahle DW, D'Arrigo RD, Krusic PJ, Cleaveland MK, Cook ER, Allan RJ, Cole JE, Dunbar RB, Therrell MD, Gay DA, Moore MD, Stokes MA, Burns BT, Thompson LG (1998) Experimental dendroclimatic reconstruction of the Southern Oscillation. Bull Am Met Soc 79:2137-2152

Touchan R, Xoplaki E, Funkhouser G, Luterbacher J, Hughes MK, Erkan N, Akkemik Ü, Stephan J (2005) Reconstructions of spring/summer precipitation for the Eastern Medi- terranean from tree-ring widths and its connection to largescale atmospheric circulation. Clim Dyn 25:75-98

Trenberth KE, Paolino DA (1980) The northern hemisphere sea level pressure data set: trends, errors, and discontinuities. Mon Wea Rev 108:855-872

Wiles GC, D'Arrigo RD, Jacoby GC (1996) Temperature changes along the Gulf of Alaska and the Pacific Northwest coast modeled from coastal tree-rings. Can $\mathrm{J}$ For Res 26:474-481

Xoplaki E (2002) Climate variability over the Mediterranean. $\mathrm{PhD}$ thesis, University of Bern, Switzerland (available at: http://www.sinus.unibe.ch/klimet/docs/phd_xoplaki.pdf)

Xoplaki E, Luterbacher J, Paeth H, Dietrich D, Steiner N, Grosjean M, Wanner H (2005) European spring and autumn temperature variability and change of extremes over the last half millennium. Geophys Res Lett 32. DOI 10.1029/ 2005GL023424 